\title{
Abundance and diversity of foliage insects among different Olericulture Crops
}

\author{
Naseem Rimsha ${ }^{1}$, Rana Naureen ${ }^{1}$, Koch Elmo Borges Azevedo ${ }^{2}$, Majeed Waqar ${ }^{1 *}$, and Nargis Shahla ${ }^{1}$ \\ ${ }^{1}$ Department of Zoology, Wildlife and Fisheries, University of Agriculture, Faisalabad. \\ ${ }^{2}$ Laboratory of Myrmecology, CEPEC-CEPLAC, Brazil.
}

Publication history: Received on 23 January 2020; revised on 29 January 2020; accepted on 10 February 2020

Article DOI: https://doi.org/10.30574/gscbps.2020.10.2.0021

\begin{abstract}
Vegetables have essential nutrients like Vitamins, minerals, antioxidants and trace elements that play a vital role in human nourishment. Insects directly or indirectly affect these vegetables. Diversity indices provide important information about species in a community and help to understand the population structure at the given place. Diversity, evenness, dominance and richness of specific taxa considered the main factors of this indices. The results after the whole research as described in methodology showed that total 389 specimens belonging to 10 orders, 33 families and 59 species were documented from spinach fields while fenugreek pertains to 327 specimens, 9 orders, 30 families, and 55 species, whereas, total 373 specimens related to 11 orders, 34 families and 61 species were documented in case of turnip. Catocala and Drosophila genus 4.89\% ( $\mathrm{N}=16)$ was recorded at their peak from Fenugreek, whereas from Turnip, Culex was documented with a high percentage of $4.02 \%(\mathrm{~N}=15)$ and from Spinach, Catocala was recorded with an utmost abundance of 4.88\% ( $\mathrm{N}=19)$. Maximum diversity, Dominance, Richness and Evenness with different values logged for Spinach and Turnip while the least number recorded for fenugreek.
\end{abstract}

Keywords: Insects; Abundance; Diversity; Spinach; Turnip; Fenugreek.

\section{Introduction}

Biodiversity is the totality and variety of distant animals and plants at all the levels of their organization from the genetic level up to the ecosystems they contain. Diversity exists from a minute creature like small microbes to gigantic types of animals and plants and it also designated as the capriciousness from all source's aquatic and terrestrial ecosystems [1, 2]. It accomplishes various functions yonder of food production, nutrient recycling, microclimate regulation, detoxification of harmful chemicals that causes threats sustainability of any ecosystem [3].

Insects considered a pivot for the endurance of any ecosystem [4]. They provide their services to humanity in different ways as a pollinator they pollinate about $80 \%$ of flowering plants, as decomposers they essential nutrients back to the environment, also important in aeration and conditioning of soil. They also play their vital role in food webs and chains and play their commercial role by providing the honey and silk [5].

Olericulture is basically the subdivision of horticultural science which corresponds with cultivation of vegetables. Vegetables not only enhance palatability but also improves appetite but also provide vitamins, minerals, dietary fiber, and phytochemicals. Some phytochemicals are strong antioxidants and modifying metabolic activation and detoxification of carcinogens. Vegetables in their diverse forms ensure adequate intake of fundamentals nutrients which contributing to solving many nutritious glitches.

\footnotetext{
${ }^{*}$ Corresponding author

E-mail address: waqarchaudhry20@gmail.com
} 
Trigonella foenum-graceum contained a medicinal substance that is used as medicines in Persia and the Middle East. It considered as old aged legumes, which has been used in combination with other vegetables [6]. Spinacia oleracea is the prince of all vegetables as it pertains the high grade of iron and other essentials bioactive compounds like a pcoumaric acid, glucuronic acid that rarely found in other vegetables, the other essentials amino acids, vitamin A and ascorbic acid increased the importance of spinach [7].

Insects damage crops by foliage feeding which leading to skeletonized leaves. The species of Aphididae, Aleyrodidae, and Pseudococcida families attack various plants, infesting leaves, stems, fruits and roots [8]. Brassica rapa (L.) leaves attacked by larvae of the specialist Plutella xylostella L. (Lepidoptera: Yponomeutidae) and herbivory by the chrysomelid beetle (Phaedonco chleariae) on Chinese cabbage [9].

By consideration of alliance of foliage insects with vegetables the extant research was performed to draw the diversity and abundance of foliage insects amongst the olericulture crops.

\section{Material and methods}

\subsection{Research site}

The study was completed to find the "Foliage insect's diversity amongst olericulture crops the study was conducted at Vegetable Research Field, Institute of Horticultural Sciences, University of Agriculture, Faisalabad (Punjab), Pakistan (Fig. 1).

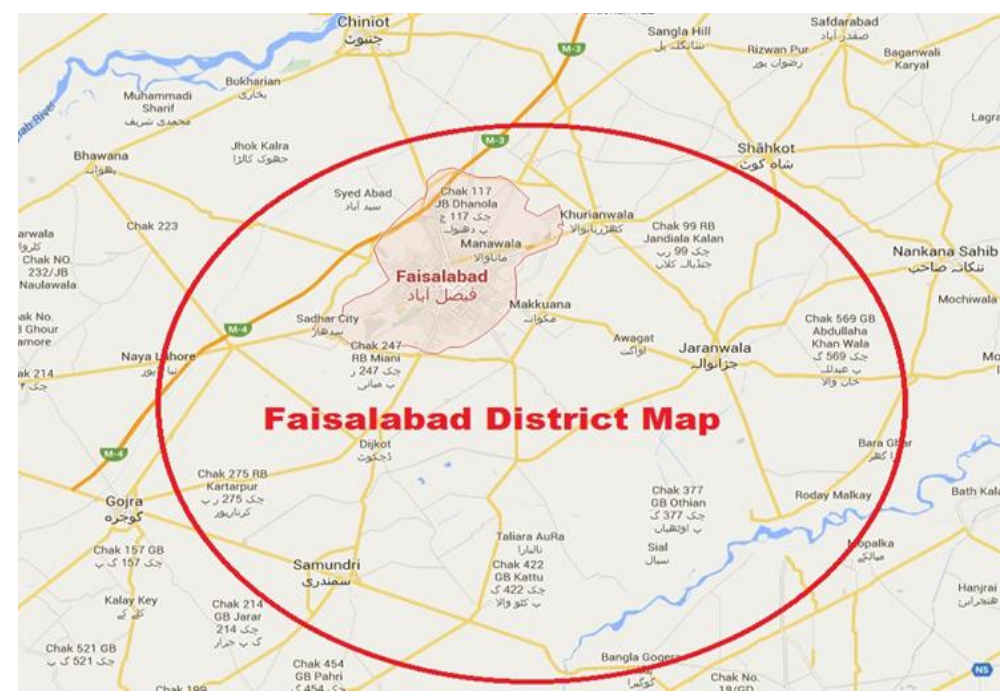

Figure 1 Map showing the study site

\subsection{Collection}

To collect the insect from fenugreek (Trigonella foenum-graceum L.), Spinach (Spinacia oleracea L.) and turnip (Brassica rapa), fields were sampled weekly for two hours at dusk and the basic tools used for collection of insect fauna: direct handpicking, sweep and aerial nets and with the aid of forceps. The samples were stored in jars containing alcohol and glycerin solution concentration of 70:30\%. After that specimen preserved and stored in isolated glass ampoules which categorized with time, date and name of vegetable sampled and sample number.

\subsection{Identification}

The collected specimens were identified with a magnifying glass, light microscope and the stereomicroscope. Collected fauna of insects was classified up to the level of species according to their taxonomy [10] and on electronic means that accessible on the internet.

\subsection{Statistical analysis}

The data organized in tabulated form in accordance with insect's morphology and taxonomical basis from order to species level. Shannon Diversity Index was used to find the various diversity indices like evenness and richness [11]. 


\section{Results and discussion}

Whole research trials completed as per maneuver, overall 1089 specimens were collected and 327 specimens from were collected from fenugreek, Turnip pertains to 373 specimens while from Spinach total 389 insects' specimens logged and they all belonged to different orders family's genus and species (Fig 2). Taxa composition and diversity of insects were studied in Faisalabad, Pakistan total 1088 specimens were documented that fitted into 8 orders, 24 families, 35 genera and 38 species [12]. The same trend was also noted in the study of [13-14].

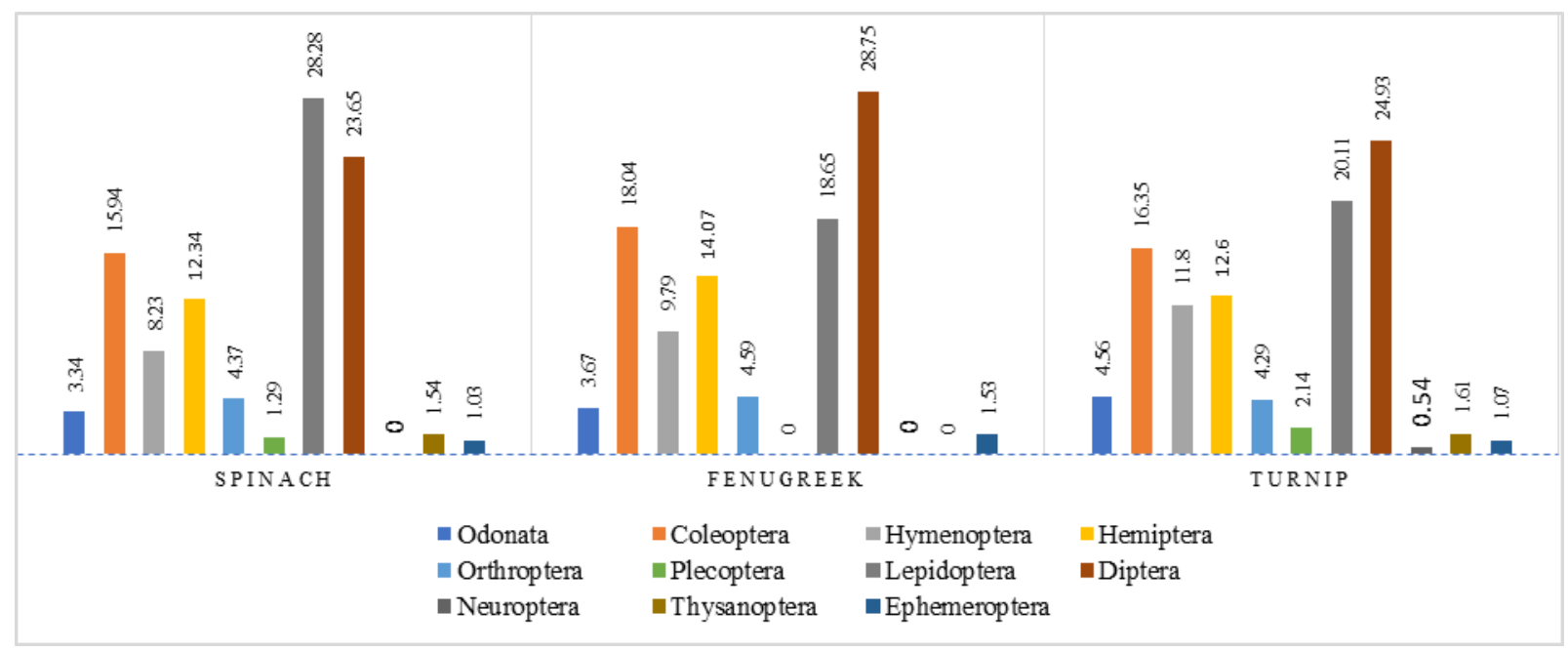

Figure 2 Order wise distribution of insects' diversity in Spinach, Fenugreek and Turnip

Chaudhary [15] found the abundance of wild pollinators on rapeseed and mustard. Devi et al. [16] documented diversity of insect pollinators in reference to a seed set of mustard. Overall documented and analyzed data from Fenugreek showed that highest abundance $2.75 \%(\mathrm{~N}=9$ ) recorded for Locusta migratoria, Meiosimyza affinis, Agallia constricta and Eupeodes corollae. But, low abundance $(\mathrm{N} \leq 5)$ documented for various species. Turnip: Maximum relative abundance from turnip field $4.02 \%(\mathrm{~N}=15)$ was noted for Culex pipiens. However minimum abundance $(\mathrm{N} \leq 5)$ was recorded for many species. Spinach: Highest abundance 3.60\% (N = 14) was documented for Platynota exasperatana But, the least relative abundance $(\mathrm{N} \leq 5)$ was chronicled for various species as shown in $($ Table 1$)$.

Table 1 Recorded relative abundance among Spinach, Fenugreek, and Turnip

\begin{tabular}{|c|c|c|c|c|c|}
\hline Order & Family & Species & Fenugreek & Turnip & Spinach \\
\hline \multirow[t]{3}{*}{ Odonata } & \multirow[t]{2}{*}{ Libellulidae } & Pachydiplax longipennis & $1.83(6)$ & $1.61(6)$ & $1.54(6)$ \\
\hline & & Sympetrum flaveolum & $1.83(6)$ & $1.07(4)$ & $0.00(0)$ \\
\hline & Aeshnidae & Anax junius & $0.00(0)$ & $1.88(7)$ & $1.80(7)$ \\
\hline \multirow[t]{12}{*}{ Coleoptera } & \multirow[t]{2}{*}{ Curculionidae } & Rhinusa tetra & $2.45(8)$ & $1.34(5)$ & $1.29(5)$ \\
\hline & & Hypera postica & $2.45(8)$ & $1.34(5)$ & $1.29(5)$ \\
\hline & \multirow[t]{4}{*}{ Coccinellidae } & Hippodamia tredecimpunctata & $2.14(7)$ & $0.27(1)$ & $1.80(7)$ \\
\hline & & Henosepilachna vigintioitopunctata & $1.22(4)$ & $1.61(6)$ & $2.06(8)$ \\
\hline & & Harmonia axyridis & $1.83(6)$ & $2.14(8)$ & $1.54(6)$ \\
\hline & & Cycloneda munda & $1.83(6)$ & $2.14(8)$ & $1.54(6)$ \\
\hline & \multirow[t]{6}{*}{ Chrysomelidae } & Altica oleracea & $1.53(5)$ & $1.34(5)$ & $0.51(2)$ \\
\hline & & Altica plustris & $0.00(0)$ & $1.61(6)$ & $1.29(5)$ \\
\hline & & Phyllotreta cruciferae & $0.61(2)$ & $0.00(0)$ & $0.00(0)$ \\
\hline & & Crepidodera fluvicirnis & $1.83(6)$ & $1.61(6)$ & $1.54(6)$ \\
\hline & & Crepidodera areola & $1.53(5)$ & $1.61(6)$ & $1.29(5)$ \\
\hline & & Phyllotreta striolata & $1.83(6)$ & $1.61(6)$ & $1.54(6)$ \\
\hline \multirow[t]{2}{*}{ Hymenoptera } & \multirow[t]{2}{*}{ Apidae } & Bombus terrestris & $3.36(1)$ & $2.95(11)$ & $1.29(5)$ \\
\hline & & Apis mellifera & $2.45(8)$ & $3.22(12)$ & $2.06(8)$ \\
\hline
\end{tabular}


Naseem et al. / GSC Biological and Pharmaceutical Sciences, 2020, 10(02), 062-069

\begin{tabular}{|c|c|c|c|c|c|}
\hline & \multirow[t]{2}{*}{ Vespidae } & Dolichovespula arctica & $1.53(5)$ & $2.41(9)$ & $2.06(8)$ \\
\hline & & Vespula vulgaris & $2.14(7)$ & $1.34(5)$ & $1.29(5)$ \\
\hline & Diapriidae & Pantoclis trisulcata & $0.31(1)$ & $1.88(7)$ & $1.54(6)$ \\
\hline \multirow[t]{9}{*}{ Hemiptera } & \multirow[t]{3}{*}{ Aleyrodidae } & Aleurocanthus woglumi & $1.83(6)$ & $1.34(5)$ & $3.34(1)$ \\
\hline & & Trialeurodes vaporariorum & $0.00(0)$ & $0.54(2)$ & $1.54(6)$ \\
\hline & & Bemisia tabacai & $1.83(6)$ & $1.88(7)$ & $1.54(6)$ \\
\hline & \multirow[t]{2}{*}{ Cicadellidae } & Amrasca biguttula & $0.92(3)$ & $1.61(6)$ & $0.77(3)$ \\
\hline & & Agallia constricta & $2.75(9)$ & $1.34(5)$ & $1.5(6)$ \\
\hline & \multirow[t]{3}{*}{ Aphididae } & Aphis craccivora & $1.83(6)$ & $1.34(5)$ & $0.77(3)$ \\
\hline & & Brevicoryne brassicae & $1.53(5)$ & $2.14(8)$ & $0.77(3)$ \\
\hline & & Acyrthosiphon pisum & $1.83(6)$ & $1.07(4)$ & $0.51(2)$ \\
\hline & Pentatomidae & Murgantia histrionicaa & $1.53(5)$ & $1.34(5)$ & $1.54(6)$ \\
\hline \multirow[t]{2}{*}{ Orthroptera } & \multirow[t]{2}{*}{ Acrididae } & Schistocerca americana & $1.83(6)$ & $1.34(5)$ & $2.31(9)$ \\
\hline & & Locusta migratoria & $2.75(9)$ & $2.9(11)$ & $2.06(8)$ \\
\hline Plecoptera & Perlidae & Acroneuria abnormis & $0.92(3)$ & $2.14(8)$ & $1.29(5)$ \\
\hline \multirow[t]{13}{*}{ Lepidoptera } & \multirow[t]{5}{*}{ Noctuidae } & Diarsia rosaria & $1.83(6)$ & $1.61(6)$ & $1.80(7)$ \\
\hline & & Apamea devastator & $1.83(6)$ & $2.68(10)$ & $1.29(5)$ \\
\hline & & Trichoplusia ni & $1.53(5)$ & $1.88(7)$ & $1.80(7)$ \\
\hline & & Spodoptera exigua & $0.00(0)$ & $1.34(5)$ & $2.31(9)$ \\
\hline & & Agrotis ipsilon & $1.22(4)$ & $1.07(4)$ & $2.57(10)$ \\
\hline & Sphingidae & Manduca sexta & $0.00(0)$ & $1.34(5)$ & $2.57(10)$ \\
\hline & Pieridae & Pieris brassicae & $1.22(4)$ & $1.34(5)$ & $2.57(10)$ \\
\hline & Nymphalidae & Aglais urticae & $1.53(5)$ & $1.34(5)$ & $1.29(5)$ \\
\hline & Coleophoridae & Coleophora albidella & $1.53(5)$ & $1.61(6)$ & $2.06(8)$ \\
\hline & Plutellidae & Plutella xylostella & $1.53(5)$ & $1.34(5)$ & $1.54(6)$ \\
\hline & \multirow[t]{2}{*}{ Erebidae } & Catocala unijuga & $2.45(8)$ & $1.34(5)$ & $2.83(11)$ \\
\hline & & Catocala palaeogama & $2.45(8)$ & $1.34(5)$ & $2.06(8)$ \\
\hline & Tortricidae & Platynota exasperatana & $1.53(5)$ & $1.88(7)$ & $3.60(14)$ \\
\hline \multirow[t]{14}{*}{ Diptera } & Tephritidae & Bactrocera cucurbitae & $2.14(7)$ & $1.88(7)$ & $1.80(7)$ \\
\hline & Agromyzidae & Liriomyza sativae & $1.53(5)$ & $1.61(6)$ & $1.80(7)$ \\
\hline & \multirow[t]{2}{*}{ Culicidae } & Culex pipiens & $3.67(2)$ & $4.02(15)$ & $2.31(9)$ \\
\hline & & Aedes albopictus & $2.75(9)$ & $1.88(7)$ & $1.29(5)$ \\
\hline & \multirow[t]{3}{*}{ Muscidae } & Spilogona falleni & $2.14(7)$ & $2.14(8)$ & $2.06(8)$ \\
\hline & & Hydrotaea ignava & $2.14(7)$ & $2.14(8)$ & $1.80(7)$ \\
\hline & & Coenosia sexmaculata & $0.31(1)$ & $2.14(8)$ & $2.31(9)$ \\
\hline & Calliphoridae & Calliphora vomitoria & $0.31(1)$ & 1.616 & $1.29(5)$ \\
\hline & Syrphidae & Eupeodes corollae & $2.75(9)$ & $1.34(5)$ & $1.80(7)$ \\
\hline & \multirow[t]{2}{*}{ Lauxaniidae } & Meiosimyza affinis & $2.75(9)$ & $1.34(5)$ & $1.29(5)$ \\
\hline & & Calliopum aeneum & $0.31(1)$ & $1.07(4)$ & $1.54(6)$ \\
\hline & \multirow[t]{2}{*}{ Anthomyiidae } & Anthomyia illocata & $1.53(5)$ & $1.07(4)$ & $1.54(6)$ \\
\hline & & Alliopsis angustitarsis & $1.53(5)$ & $1.34(5)$ & $1.54(6)$ \\
\hline & Drosophilidae & Drosophila funebris & $1.83(6)$ & $1.34(5)$ & $1.29(5)$ \\
\hline Neuroptera & Chrysopidae & Chrysopa perla & $0.00(0)$ & $0.54(2)$ & $0.00(0)$ \\
\hline Thysanoptera & Phlaneothripidae & Gynaikothrips ficorum & $0.00(0)$ & $1.61(6)$ & $1.54(6)$ \\
\hline Ephemeroptera & Siphlonuridae & Siphlonurus spectabilis & $1.53(5)$ & $1.07(4)$ & $1.03(4)$ \\
\hline Total & & & 327 & 373 & 389 \\
\hline
\end{tabular}


The order and family-wise summary of the distribution of insect's diversity fenugreek turnip and spinach was recorded: According to this from spinach, maximum abundance was recorded for Hymenoptera 28.8\% and from fenugreek and turnip order Diptera was recorded with the maximum number of species $29 \%$ and $25 \%$ respectively. The orders with respect to the number of individuals in the different sites were as follows: Orthoptera (32\%), Coleoptera (17\%), Hemiptera (15\%), Diptera (12\%), Hymenoptera (10\%), Odonata (7\%) and Lepidoptera (7\%). A maximum number of species was recorded that belonged to Orthoptera and others respectively and these species were found in both sites (Fig. 2). This trend has also been recorded previously as described by Chakraborty et al. [17] 0 Diptera (42\%), Coleoptera (18\%), Orthoptera (11\%), Hymenoptera and Lepidoptera (8\%), Hemiptera and Araneae (5\%) and Neuroptera (3\%). Family distribution was also documented and observed that Chrysomelidae was present in the maximum number (Fig. 3). From Spinach and Turnip fields Noctuidae was documented maximum (Fig. 4, 5).

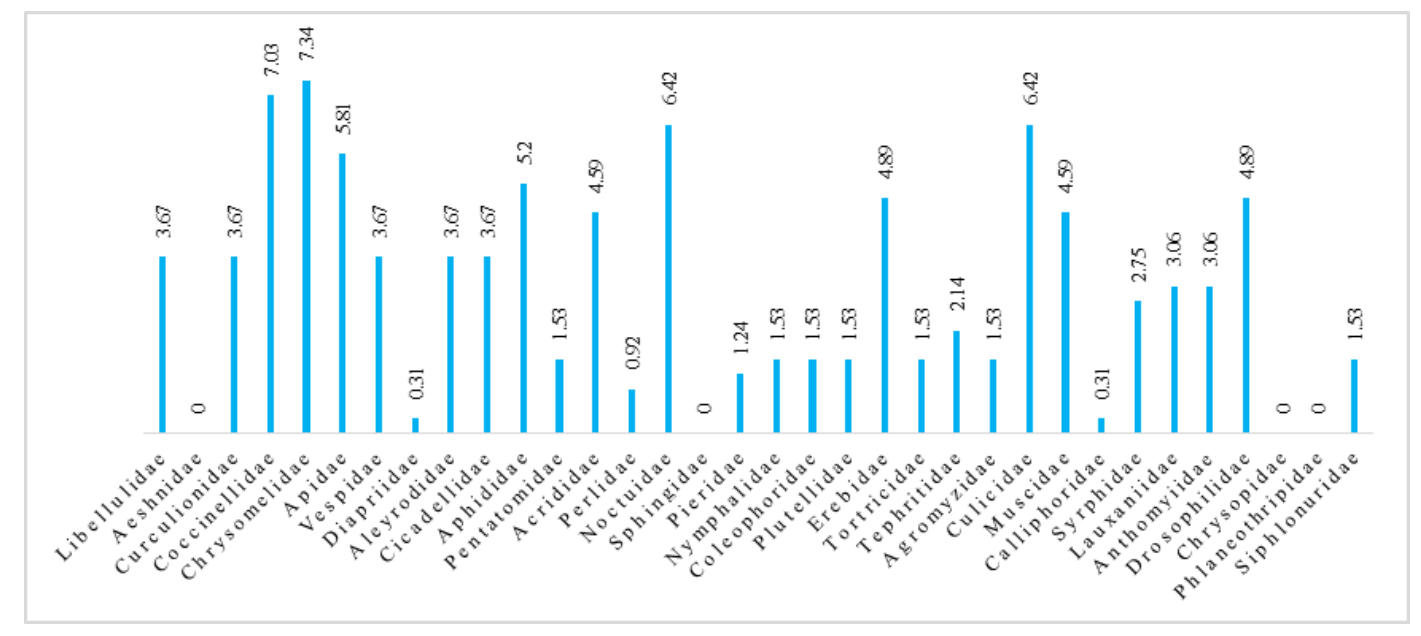

Figure 3 Family-related distribution of insects' diversity in Fenugreek

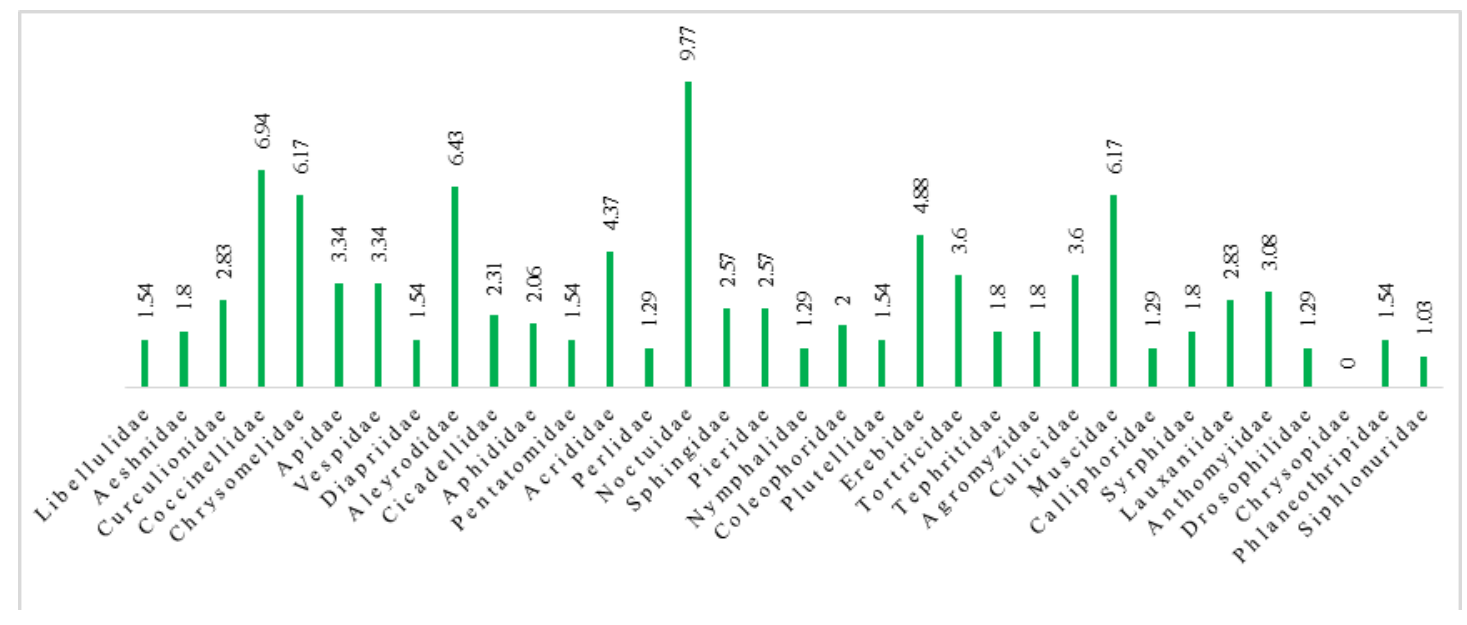

Figure 4 Family-related distribution of insects' diversity in Spinach 


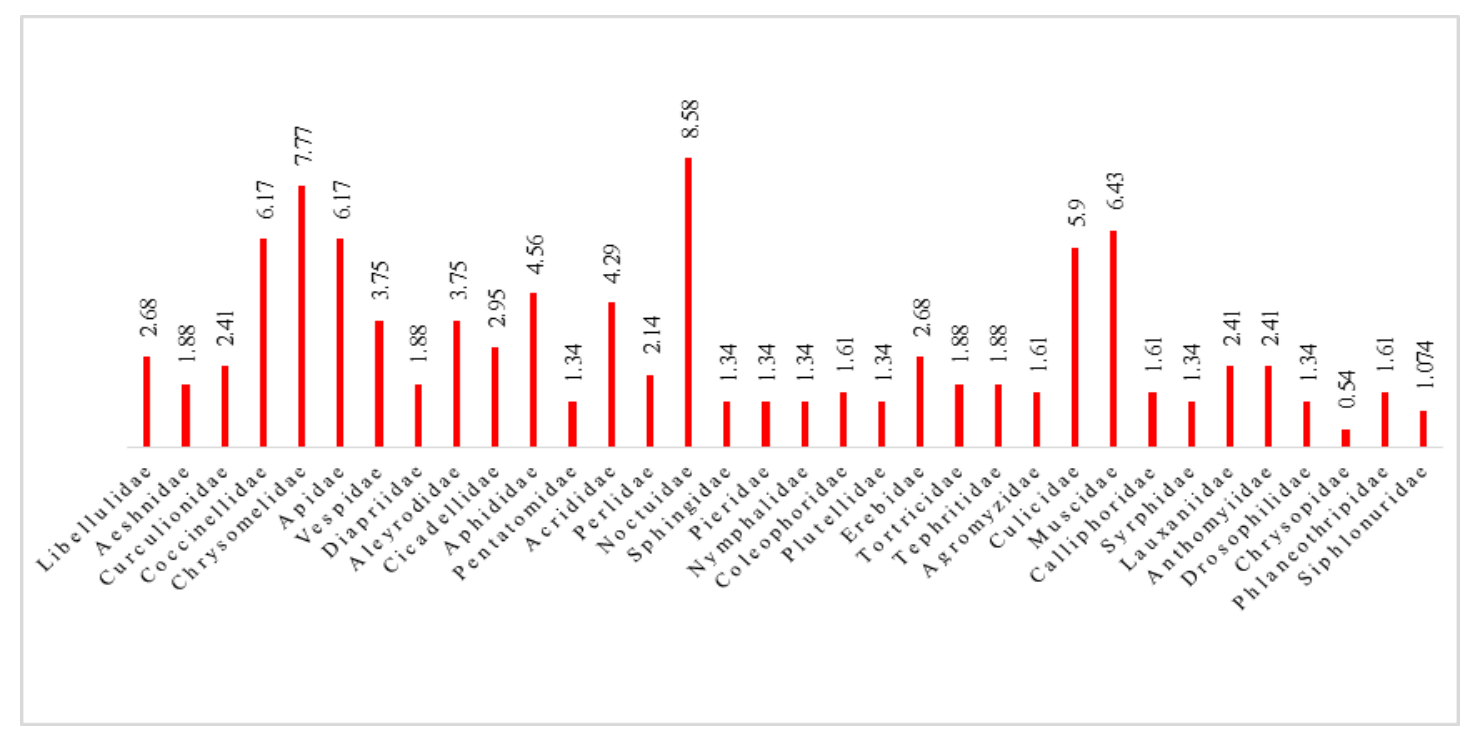

Figure 5 Family-related distribution of insects' diversity in Turnip

It considered important as they provide the pivot knowledge about rareness and commonness of species in a community. So, keeping in view the importance of these aspects, calculations were complete by the Shannon Diversity Index [18]. It was chronicled high from Turnip and Spinach while Diversity Maximum $\left(\mathrm{H}^{\prime}{ }_{\max }\right)$ was logged highest for turnip and spinach. Evenness was noted extraordinary for turnip and spinach. Dominance was documented supreme for Spinach and Turnip (Fig. 6) [19]. Found the diversity indices for inland terrestrial insects. Richness was noted highest for Turnip and Spinach. Diversity composition of insects was recorded higher in the case of bitter gourd in the morning time [20].

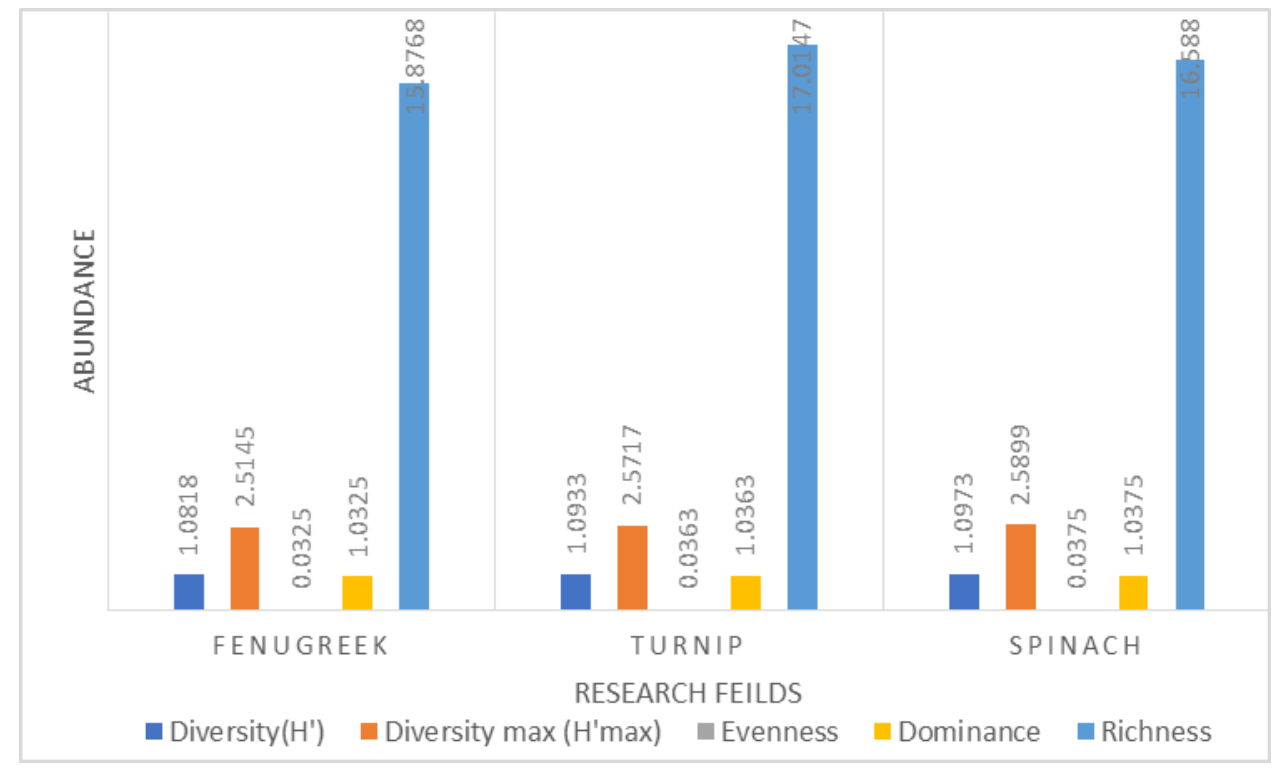

Figure 6 Record of diversity indices from research fields

\section{Conclusion}

The diversity of insects was recorded for three fields viz. Spinach, Turnip and Fenugreek and it concluded that there is a significant difference in diversity and abundance among the fields. Maximum abundance was recorded from the spinach field. Species richness, abundance and diversity was documented also maximum for spinach fields that evaluate the significant difference of diversity among fields. This study was pre-requisites for any management strategies. 


\section{Compliance with ethical standards}

\section{Acknowledgments}

We are thankful to Biodiversity Laboratory, Department of Zoology, Wildlife and Fisheries, University of Agriculture, Faisalabad for providing us all the facilities for conduction of research. All the authors contributed equally in this work.

\section{Disclosure of conflict of interest}

Authors have no conflict of interest to declare.

\section{References}

[1] Rathore A and Jasrai YT. (2013). Biodiversity: importance and climate change impacts. International Journal of Science Research and Publications, 3, 1-5.

[2] Glowka L. (1994). A guide to the convention on biological diversity. Environmental Policy and Law, 30-161.

[3] Alteiri M. (1999). The ecological role of biodiversity in agro-ecosystems. Agriculture Ecosystem and Environment, 74, 19-31.

[4] Auerswald L and Lopata A. (2005). Insects diversity and allergy. Current Allergy Clinical Immunology 18, 58-60.

[5] Costanza R and Folke C. (1997). Valuing ecosystem services with efficiency, fairness and sustainability as goals. Journal of Chemistry and Ecology, 49-70.

[6] McAnuff MA, Omoruyi FO and Morrison EYSA. (2002). Plasma and liver lipid distributions in streptozotocininduced rats fed sapogenin extract of the Jamaican bitteryam (Dioscorea polygonoides). Nutrition Research, 22, $1424-1434$.

[7] Pandjaitan N, Howard LR, Morelock T and Gill M. (2005). Antioxidant capacity and phenolic content of spinach as affected by genetics and maturation. Journal of Agriculture and Food, 53, 8618-8623.

[8] Blackman RL and Eastop VF. (2000). Aphids on the world's crops. An Identification information guide, 466.

[9] Rostas M, Bennett R and Hilker M. (2002). Comparative physiological responses in Chinese cabbage induced by herbivory and fungal infection. Journal of Chemistry and Ecology, 28, 2449-2462.

[10] Borror DJ and Delong DM. (2005). An introduction to the study of insects. Columbus, Ohio, 812.

[11] Magurran AE. (1988). Ecological diversity and its measurement. Princeton Uni. Press, New Jersey, 34-37.

[12] Rana N, Saleem M, Majeed W, Jalal F, Ehsan N and Nargis S. (2019). Diversity of arthropods regarding habitat specialty in agro-ecosystem of Faisalabad, Pakistan. GSC Biological and Pharmaceutical Sciences, 6(2), 01-08.

[13] Rana N, Ushna BR, Muhammad ZI, Iqra A, Shahla N and Zunaira S. (2017). Assortment and comparative abundance of foliage insects on lemon (Citrus limon L.) and fruiter (Citrus reticulata Blanco cv. Feutrell's Early). Journal of Entomology and Zoology Studies, 5(6), 459-465.

[14] Rana N, Imran M, Bukhat T, Khan AS, Fatima K, Javed S, Fatima S and Iqbal MZ. (2018). Prevalence pattern and susceptible strains of order Diptera, Lepidoptera and Coleoptera among Sarson (Brassica campestris) fields under different ecological conditions. Journal of Entomology and Zoology Studies, 6, 33-40.

[15] Chaudhary OP. (2001). Abundance of wild pollinators on rapeseed and mustard. Insect Environment, 7(3), 141142.

[16] Devi M, Harish KS, Raj KT, Satish KB, Kiran R, Meena T and Budhi R. (2017). Diversity of insect pollinators in reference to a seed set of mustard (Brassica juncea L.). International Journal of Current Microbiology and Applied Sciences, 6(7), 2131-2144.

[17] Chakraborty A, Kumar and Rajadurai KG. (2014). Biodiversity of insect fauna in Okra (Abelmoschus esculentus (L.) Moench) ecosystem. Trends in Biosciences, 7(16), 2206-2211.

[18] Shannon CE. (1948). A mathematical theory of communication. Journal of Bell. Systematic \& Technology, 27, 379-423. 
[19] Tewari M, Poonam BD and Kaushal R. (2006) Diversity of terrestrial insects in a cultivated land of Tarai region of Kumaun, Uttaranchal. Entomology, 31, 207-216.

[20] Abid K and Rana N. (2019). Diversity and abundance of foliage insect communities in Bitter gourd Field with regards to diurnal rhythm of insects within Faisalabad, Pakistan. Asian Journal of Advances in Agriculture Research, 9(2), 1-12.

\section{How to cite this article}

Naseem R, Rana N, Koch EBA, Majeed W and Nargis S. (2020). Abundance and diversity of foliage insects among different Olericulture Crops. GSC Biological and Pharmaceutical Sciences, 10(2), 62-69. 